\title{
Chromosomal Q-Heterochromatin and Atherosclerosis
}

\author{
A. I. Ibraimov ${ }^{1}$ \\ ${ }^{1}$ Kyrgyz Institute of Balneology and Physiotherapy, Bishkek and Laboratory of Human Genetics, National Center \\ of Cardiology and Internal Medicine, Togolok Moldo str. 3, Bishkek, 720040, Kyrgyzstan \\ Correspondence: A. I. Ibraimov, Kyrgyz Institute of Balneology and Physiotherapy, Bishkek and Laboratory of \\ Human Genetics, National Center of Cardiology and Internal Medicine, Togolok Moldo str. 3, Bishkek, 720040, \\ Kyrgyzstan. Email: ibraimov_abyt@mail.ru
}

Received: September 26, 2017

Accepted: October 12, 2017

Online Published: October 19, 2017

doi:10.5539/jmbr.v7n1p143

URL: https://doi.org/10.5539/jmbr.v7n1p143

\begin{abstract}
We suppose that at study of the pathogenesis of atherosclerosis, it is possible that some evolutionary aspects of the problem are missed. This aspect is related to the peculiarity of human adaptation to climatic geographic conditions of Eurasia, which differ significantly from the climate of East Africa, where Homo sapiens was formed as a tropical biological species and so it has remained to this day. A hypothesis has been put forward that the pathogenesis of atherosclerosis is associated with some previously unknown features of the genome and the physical properties of the human body that arose in the process of its adaptation to a mild and cold climate. These adaptive genetic changes that have contributed to the development (settling) by Homo sapiens of non-tropical, including cold and high mountain areas of the Earth, resulted to the fact that a man became the single species vulnerable (predisposed) to atherosclerosis.

Atherosclerosis is apparently a purely human disease that appeared after adaptation of man to climatic conditions of temperate and northern latitudes of the northern hemisphere. The type of vessels (arteries or veins) and the site of their lumen have no role in the development of atherosclerotic changes. The primary and main causative factor in the development of atherosclerosis is blood temperature. The degree of blood cooling in the lungs depends on geographical latitudes and altitude above sea-level of the site of permanent residence of man. The preclinical stage of atherosclerosis may develop into a pathological form predominantly in individuals in the genome of which the amount of chromosomal Q-heterochromatin material is higher than its mean value per individual in the population.
\end{abstract}

Keywords: atherosclerosis, coronary heart disease, blood temperature, chromosomal Q-heterochromatin, human adaptation, human body heat conductivity

\section{Introduction}

"Equality is a social doctrine and variation is the biological norm. The overwhelming determinant of the variable human form and response is not genetic but environmental.

Indeed, the variability of environment to which humans are exposed is the conspicuous and challenging social reality of our times."

Th. Dobzhansky. American Biology

Teacher, 1973, 35: 125-129.

Exactly how atherosclerosis begins or what causes it isn't known, but some theories have been proposed. Many researchers think atherosclerosis begins because the innermost layer of the artery (endothelium) becomes damaged. Possible causes of damage to the arterial wall are free-radical reactions, elevated levels of oxidated serum cholesterol, triglycerides, fibrinogen and homocysteine, high blood pressure, obesity, lifestyle issues, cigarette smoke, and environmental pollutants.

For more than half a century, the relationship between dietary factors and coronary heart disease (CHD) has been a major focus of health research. Contrary to the established view, current data suggest that dietary cholesterol is not a primary factor of or causes of heart disease - with the possible exception of the genetic forms of familial hypercholesterolemias. For instance, recent clinical trials evaluating the effect of cholesterol-lowering drugs on the development of chronic heart failure, diabetes and stroke have yielded disappointing results. On the other hand, 
an unbalanced omega-6/omega-3 fatty acid ratio and a cholesterol intake not consistent with the amount during evolution seem to be causal factors in the development of CHD (Simopoulos \& De Meester, 2009).

The modern man is the only livings being who has mastered the entire land of the Earth, remaining at this a single tropical biological species. For this a man is indebted, as we believe, to two closely interconnected evolutionary processes that are not characteristic to other species of animals: 1) the presence in its genome of a special genetic material - chromosomal Q-heterochromatin regions - that exist in chromosomes only in three higher primates (Homo sapiens, Pan troglodytes and Gorilla gorilla). However, unlike chimpanzees and gorillas this kind of heterochromatin in the human population is distinguished by a wide quantitative hereditary variability; and 2) human bodies in the population differ significantly in their heat-conducting characteristics, and their level depends on the number of chromosomal Q-heterochromatin regions (Q-HRs) in its genome.

We suppose that atherosclerosis is apparently a purely human disease that appeared after adaptation of man to climatic conditions of temperate and northern latitudes of the northern hemisphere. We call into question the existing views asserting that: (a) the blood temperature in the left heart and the right heart should always be equal although no one and nowhere has specially checked such a possibility; (b) a high content of atherogenous substances (fats, lipoproteins, fibrinogen filaments and etc.) in plasma is a sufficient and necessary condition for development of common forms of atherosclerosis.

From our point of view, the primary and main causative factor in the development of atherosclerosis is blood temperature. We also assert that the temperature of the blood in the right heart and left heart is different; in the second should be lower than in the first, because in the process of breathing the blood will be cooled. At this the degree of blood cooling in the lungs depends on geographical latitudes and altitude above sea-level of the site of permanent residence of man. Moreover, effect of cooled blood on atherogenic substances in plasma (phase transition of lipoproteins, fibrous elements and other atherogenous substances in plasma from "liquid" to "solid" state) must be different depending on the temperature of the blood and the level of body heat conductivity (BHC) of individuals in the population.

\section{State of the Problem}

Atherosclerosis - an endemic and lethal disease of modern man, is plurifactorial in origin and multiform in character. Atherosclerosis is an abnormal response of some areas of vascular wall to the cumulative and often synergetic effects of episodic injury-repair processes, causing permanent arterial damage.

To-date, owing to the efforts of many investigators, quite a number of reliable data have been obtained on the pathogenesis of the atherosclerosis including the discovery of the so-called primary and secondary risk factors of the atherosclerosis. The most known ones:

- in the westernized societies, atherosclerosis is the underlying cause of about $50 \%$ of all deaths. There are many examples of the development of extensive atherosclerosis in subjects who during dozens of years consciously consumed food low in fat and cholesterol; on the other hand, it may be absent in elderly subjects who during many years consumed food excessively rich in cholesterol;

- atherosclerosis is a progressive disease characterized by the accumulation of lipids and fibrous elements in the large arteries;

- coronary atherosclerosis appears more severe in men than in premenopausal women. Below age 60 , men develop CHD at more than twice the rate of that in women;

- pronounced atherosclerotic changes are observed at the site of division of the carotid artery into an external and internal one. In the trunk of the common carotid artery changes

- are always weaker and mainly have the appearance of lipid spots without the development of connectivetissue thickenings;

- in cerebral arteries atherosclerotic changes are most developed in those of the base of the brain and in their larger branches. In contrast, in small brain substance arteries atherosclerotic changes occur rarely and only as small lipid spots;

- in both blacks and whites, atherosclerotic involvement was significantly higher in North America than in similar groups from Central and South America;

- among the "whites" of the UK, death rates caused by CHD are non-uniform: more frequent deaths occur in the North, less frequently in the central part and still less in the southern part of the country; 
- CHD is apparently commoner in South Asians (India, Pakistan, Bangladesh and Sri Lanka) in Britain than in general population, despite lower levels of several classic coronary risk factors;

- there also exist regional differences in the continental Europe: high death rates caused by CHD are observed more among East Europeans than in France and Spain;

- in the pulmonary artery system atherosclerotic changes, even in pronounced general atherosclerosis, have the appearance of "fatty streaks» which are mainly situated not in the common trunk but in the right and left pulmonary arteries. Pulmonary artery atherosclerosis is usually encountered not as an independent disease but as pathological process that develops in certain heart diseases (mitral stenosis, congenital heart diseases) and lung diseases (emphysema, pulmonary hypertension);

- atherosclerosis does not occur in wild life animals.

Three primary risk factors that have been identified for premature CHD are hypercholesterolaemia, hypertension, and smoking. When speaking about hypercholesterolaemia, it is a common belief that the deleterious effects of excess plasma low-density lipoprotein (LDL) cholesterol is that the LDL enters the artery wall, is chemically modified, and then is recognized by a special class of receptors, called macrophage scavenger receptors, that mediate the cellular accumulation of the LDL cholesterol in the artery, eventually leading to the formation of an atherosclerotic lesion.

Hypertension is the most important single risk factor for CHD, and particularly for cerebral hemorrhage; hypertension increases lateral pressure, turbulence, and limits arterial wall pliability, resulting in increased stiffness of the inner vascular layers. The importance of mechanical forces in atherosclerotic plaque formation is suggested by the observation that lesions have a predilection for developing in areas of disturbed flow such as bifurcation and bends in the circulation (Glagov et al., 1988).

Smoking is the third risk factor in CHD, and numerous clinical reports describe an association between smoking and peripheral atherosclerosis. Its effects are independent of other risk factors such as hypercholesterolaemia and hypertension, although smoking may exacerbate the actions of other risk factors on CHD. However, the mechanism of pathogenic effects of tobacco smoke on atherogenesis is still not clear.

Several secondary risk factors also have been identified, including elevated serum triglycerides, diabetes mellitus, obesity, and lack of physical activity, stress, and a tense, over conscientious personality.

However, exactly how atherosclerosis begins or what causes it isn't known (Ross, 1993; Lusis, 2000).

\section{The Proposed Hypothesis of the Atherosclerosis Pathogenesis}

\subsection{Major Prerequisites}

Our hypothesis is based on the following prerequisites: 1) man was and remains the only tropical biological species whose ancestors, with the exception of the last 30-50 000 years, lived permanently under the conditions of a tropical climate; 2 ) atherosclerosis is apparently a purely human pathology and it could come into existence only after man was able to leave the bounds of his original native land (tropical Eastern Africa); 3) the atherosclerotic process can develop into a pathology under conditions different from the climate of tropics, i.e., there where man breaths cold air during a definite period of the day or year; 4) the frequency and severity of the atherosclerotic process increase as the geographical latitude and altitude above sea-level increase; 5) the possible cause of the deposition of "fatty streaks" in vascular walls is blood cooling after pulmonary circulation; 6) the first portion of cooled blood enters into aorta and then carotid and carotid arteries and so on; 7) since blood itself does not produce heat, it is heated passively during its circulation in the body; 8) the absence of atherosclerotic changes in veins, including the pulmonary artery, is due to the fact that warm $\left(37.0^{\circ} \mathrm{C}\right)$ blood always circulates in normal states; 9$)$ the most frequent location of atherosclerotic changes on arteries at the base and not in the thickness of the brain substance is due to the relatively low arterial blood temperature in the circle of Willis; 10) the "atherogenic" effects of cooled blood should be, for thermophysical and hydrodynamic reasons, most pronounced in those vascular areas where prevails turbulent and not laminar blood flow, in other words, where there are bifurcations and branching, and in the heart contraction of ventricular muscles also creates regular squeezing of the coronary vessel lumen (Ibraimov, 2008).

\subsection{Pathogenesis of Atherosclerosis}

We are of the opinion that the sequence the initial, preclinical stage of the development of atherosclerosis is as follows: blood entering into the lungs, coming into contact with cold inhaled air, is cooled $\rightarrow$ during gas exchange a part of $\mathrm{O}_{2}$ and $\mathrm{CO}_{2}$ dissolves in plasma lipids $\rightarrow$ as temperature falls blood viscosity increases $\rightarrow$ during systole in the left ventricle and the aorta, as well as at the site of bifurcation and branching of coronary and cerebral vessels 
there is a turbulent blood flow leading to the formation of temporary fatty droplets in plasma $\rightarrow$ in these droplets there are fats, lipoproteins, fibrinogen filaments, $\mathrm{O}_{2}, \mathrm{CO}_{2}$ and other substances and molecules the amount of which depends upon their concentration in plasma $\rightarrow$ under the influence of aortic pressure and turbulent blood flow these fatty droplets damage the vascular endothelium and are gradually diffused, primarily into the aortic intima then into coronary, cerebral and others arteries $\rightarrow \mathrm{O}_{2}$ molecules in the droplets diffuse into the intima, oxidate a part of the lipoproteins and convert them into oxidized LDLs. This is already the beginning of inflammatory processes within the vascular wall. To say easier, then cholesterol, fibrin and other substances penetrate into the walls of the arteries that begin to clog vessels, narrowing them. All that is known about subsequent processes has already been described in detail (Ross, 1993; Lusis, 2000).

In essence, our hypothesis of the initial stage of atherogenesis is based on three interrelated physical processes: a) a local decrease in the blood temperature below $37.0^{\circ} \mathrm{C}$ in the initial section of the systemic circulation when breathing cold ambient atmospheric air; b) the transformation of some plasma lipoproteins and fibrous elements from "liquid" to a relatively "solid" state with the blood temperature drop below $37.0^{\circ} \mathrm{C}$; c) emergence of transient microscopic droplets of "solid" particles in the plasma due to turbulence, the former being capable of mechanical lesion of endothelium in the walls of larger arteries.

Here we would like to introduce some necessary clarity. Neither we nor anyone else have at present data on direct temperature measurements, be it in lung capillaries during entry or in the left heart and right heart. Nevertheless there are sufficient grounds to suppose that blood temperature in the left atrium, ventricle, aorta, coronary and cerebral vessels should be lower than core temperature in the other parts of the body. Thus, in adults at rest effective surface area of pulmonary capillaries is equal to about $60 \mathrm{~m}^{2}$, while the maximal area is $90 \mathrm{~m}^{2}$. Pulmonary capillaries are characterized by a rather considerable diameter: their length is not great, and they form thick nets around the alveoli. Their endothelium is of a "compact" type, while the thickness of the membrane separating alveoli and capillaries amounts to no more than $0.25-0.5 \mathrm{mkm}$. The total content of blood in capillaries ranges from about 70 to $100 \mathrm{ml}$, amounting to $12-15 \%$ of the total blood volume in the lungs (Folkow \& Neil, 1971). In addition, as blood leaves the heart and travels in the larger arteries, its temperature remains essentially constant with little equilibration taking place. Finally, the rarefaction of air during inspiration in the cavity of the alveoli further contributes to the cooling of the inhaled air.

Reaching the arterioles, blood will be essentially at tissue temperature, following then the local changes of tissue temperature. In metabolically active tissues, such as skeletal muscle during exercise, temperature can be elevated by several degrees Celsius. An exercising person generates heat at a near-kilowatt rate for hours. For example, marathon runners have sustained rectal temperature of $40^{\circ} \mathrm{C}$ and $41^{\circ} \mathrm{C}$ (Adams et al., 1975). Thus, arterial temperature at the initial section of the systemic circulation should rise "gradually" as blood travels from the left ventricle: aorta $\rightarrow$ coronary vessels $\rightarrow$ cerebral arteries etc. Venous temperature is changed by mixing of blood from warmer and cooler areas, finally attaining central blood temperature (Werner \& Brinck, 1997). Even these indirect but objective data suggest that during inhalation of cold air blood temperature in the lungs should decrease below $37^{\circ} \mathrm{C}$.

Before substantiating the initial stage of atherosclerosis let us recall phase transition of liquid to crystal. Crystal is a state of matter where atoms or molecules are located in space regularly (periodically). We usually know crystals as solids. Glass, although being a solid state of matter, is not crystal. The atoms are dispersed chaotically in it. It is an amorphous solid. Current physical views are that phase transition of liquid to crystal occurs in pure (without dirt) liquid at a precisely defined temperature. Liquid to solid change in amorphous solids occurs under a wide range of temperatures.

Now let us pay attention to some of rather remarkable properties of lipids. Thus, it has been established that each lipid species is characterized by a gel-liquid crystalline phase transition temperature (PT) (Chapman, 1976) below which the fatty acid chains are in a quasicrystalline array, and above which the chains are in a more mobile or "fluid" state. All naturally occurring lipids are characterized by a heterogeneity in their fatty acid moieties. Lipids with defined fatty acid side chains have been synthesized. These are dioleoyl (DOPC) - dipalmitoyl (DPPC) and dimerystoyl (DMPC) - phosphatidylcholines, which contain oleic, myristic and palmitic acids, respectively. They have different PT: DOPC are in the liquid crystalline state at temperatures above about $-20^{\circ} \mathrm{C}$, whereas DMPC and DPPC vesicles "melt" at about $21^{\circ}$ and $36^{\circ} \mathrm{C}$, respectively (Lentz et al., 1976). Unfortunately, phase transition characteristics of well-known atherogenous lipoproteins and other human plasma components are generally not investigated at all. But we think that phase transition is a crucial part in the initial stage of atherosclerosis development.

It is known that maintenance of essentially stable core temperature within very narrow limits is the basic thermodynamic condition for normal existence of warm-blooded animals including man because the biochemical 
reactions velocities depend exponentially on the temperature. Its slight variations can change the reaction velocity multifold, which is incompatible with life.

Therefore, if a phase transition occurs in a living organism, it should be the transition of only the first order, i.e. of the liquid to crystal type. We do not speak here of the phase transitions of the second order also occurring within a narrow temperature interval since we do not think it related to the issue in question (Rothen \& Pieanski, 1986).

Thus, we assume that a slight decrease in the blood temperature is, possibly, leading to the phase transition of a part of some plasma moieties to the liquid crystal state. Experiments are known to have been performed on transition of synthetic lipids from liquid to a liquid crystal state that occurs at $36-37^{\circ} \mathrm{C}$ (Cantor \& Schimmel, 1980). Since it is the lipoproteins that transfer cholesterol in blood, in view of the above we believe that when the blood temperature in alveoli is lowered liquid crystalline micro crystals of lipoproteins are formed in the plasma. Since by their mechanical properties the liquid crystals are an intermediate state of matter between liquids and solids, they exert a stronger mechanical effect when impacted against the blood vessel walls as compared to liquids.

Lipoprotein micro crystals cannot substantially impair the walls of venous vessels because of their little kinetic energy. Therefore, atherosclerotic changes are usually not present in the veins.

When micro crystals get to the heart together with the blood flow they participate with it in the turbulent movement generated during this pump pulsations. It is known that coagulation of micro formations may occur in turbulent movements (in the same way as cream is formed of micro drops of fat in the separator). We believe that micro crystals grow in plasma using the same mechanism.

On leaving the heart the blood travels for some time yet in a turbulent manner. The full-grown crystals possessing a sufficiently large size and thus a kinetic energy may mechanically lesion the inner vascular layers of larger bloodvessels. We should note here that the turbulent flow of liquid blood (i.e. without micro crystals) cannot impair the vascular walls due to some hemodynamic considerations: the tensile stress on the artery walls, which makes the lesion of a layer of endothelium cells possible, should be $10 \mathrm{~N} / \mathrm{m} 2$. It was established, however, that under ordinary conditions the tensile stress in the blood-vessels is much lower than the above mentioned value and reaches, e.g. for ascending aorta, $0.43 \mathrm{~N} / \mathrm{m}^{2}$.

It is known that temperature has a great influence on fluid viscosity. The possible influence of low temperature on blood viscosity is also intensified by the fact that fibrinogen molecules having an elongated shape increase internal friction of a solution. Thus, the length of the fibrinogen monomers according to data of atomic force microscopy averaged $65.8 \mathrm{~nm}, 1.4$ times the value determined by electron microscopy (Taatjes et al., 2001). It is likely that fats and plasma lipoproteins also influence blood viscosity if blood temperature decreases.

In all the peripheral vessels blood flow is of a laminar nature. However, in normal states there is turbulence in the ventricles and to a certain extent in atria and the aorta. Turbulent blood flow also takes place in sites of bifurcation and branching of central vessels (Folkow \& Neil, 1971). Moreover, internal walls of these arterial areas differ in the morphology of endothelial cells (polygonal) which are believed to be damaged more frequently under the influence of turbulent blood flow (Ross, 1993; Lusis, 2000). Apparently, under the influence of turbulent flow temporary minute fatty droplets are formed (e.g. like when milk is whipped), and these droplets disappear as normal blood temperature is restored and turbulent flow becomes laminar. In a turbulent flow of fluid there is a great loss of energy, as energy expenditure in creating kinetic energy in turbulences increases. It is the energy that "drives" fatty droplets into the vascular intima. Let us note that turbulent flow is not peculiar to peripheral blood flow provided, of course, that there are no obstacles there (e.g. atherosclerotic plaques) which promote local development of turbulence.

Frequent cerebral artery lesions are apparently explained by the exceptional features of cerebral blood supply. It is known that in cerebral arteries atherosclerotic changes are most developed in those of the base of the brain and in their larger branches. In contrast, in small brain substance arteries atherosclerotic changes occur rarely and only as small lipid spots. The brain of an adult man weighing about $1400 \mathrm{~g}$ receives approximately $50-60 \mathrm{ml}$ of blood per minute $/ 100 \mathrm{~g}$ at rest, i.e., about $750 \mathrm{ml}$. The brain consumes $3-3.5 \mathrm{ml}$ of oxygen per minute per $100 \mathrm{~g}$, i.e., almost $20 \%$ of all the oxygen consumed by the organism at rest (Folkow \& Neil, 1971). Moreover, internal carotid and vertebral arteries forming the basilar artery combine into a Willis' circle at the base of the brain and ensure all of its blood supply. Since the distance between the aortic arch and the base of the brain is short and straight, and carotid arteries lie close to the surface of the body, almost under the skin, blood temperature apparently has no time to reach $37^{\circ} \mathrm{C}$ if cold air is inhaled. Possibly, the base of the brain, unlike the brain substance itself, is not the most "warm place" in the cranial box rapid heating of blood, as this part lies very close to the nasopharinx, frontal and maxillary sinuses which, among other things, are also engaged in heating inhaled air. 


\subsection{Other Evidences Supporting this Idea}

Since at present we have no key data (blood temperature after its entry into the right and left heart and the aorta, as well as into the coronary vessels and cerebral arteries), let us also present a number of indirect data as to the relatively possible role of temperature in general in the development of atherosclerosis.

Perhaps it is worth mentioning here the phenomenon of restenosis. As it is known, the principal surgical approaches to the treatment of atherosclerosis are bypass drafting, endarterectomy, and percutaneous transluminal angioplasty. Angioplasty has escalated rapidly to over 250000 procedures per year in the United States alone. However, the most common problem is restenosis, which occurs in about 30-50\% of the patients within 3 to 6 months of the procedure. These observations are confirm in addition the plausibility of our hypothesis that blood temperature and not the type of vessels plays an important role in the development of atherosclerosis, for in this case atherosclerosis develops very rapidly on the walls of veins if they are taken as transplants, which doesn't occur in normal states.

Epidemiologists-cardiologist constantly remind us that the spontaneously formed nature of the diet in modern economically developed countries is in essence atherogenic and contributes to the incidence of CHD, as highcaloric food prevails, predominantly rich in saturated fats. As for as we feel that food is undoubtedly an important but not chief requisite for the development of atherosclerosis, taking into account the fact that in developing countries situated in the tropical zones of Africa, Asia and America atherosclerosis is not a such a topical medico social problem as in westernized societies, despite the fact that significant social strata of the population there the nature of the diet in which is comparable to that in the rich West.

Let us analyze the results of epidemiological studies. Thus, data of a co-operative international study in seven European countries that were carried out in the sixties clearly indicate the importance of the factor of geographical latitude. In particular, as concerns mortality from CHD the first place belongs to Finland, to the Netherlands - the fourth, and to Greece - the last. In the same report data on the incidence of CHD are presented (death from CHD, infarction, angina pectoris and other form of CHD) per 10000 subjects per year among males aged 40 to 59 years in a number of countries of the world, and they were arranged in the following order: Japan (15-20), Greece (32), Yugoslavia (53), Italy (100), the Netherlands (139), USA (railroaders, 177) and Finland (198) (Keys, 1970).

A low incidence of CHD is known in India, which is associated by cardiologists with the low level of known risk factors in that country (Servotham \& Berry, 1968; Dewan et al., 1974). But in our opinion the example of Taiwan contradicts traditional views. Thus, according to data obtained from the examination of a casual sample consisting of 6721 subjects aged 40 and over 40, the incidence of CHD proved to be 3.5\% among males and 3.8\% among females, i.e., three times lower than in the USA (Tzeng, 1972).

Mortality from CHD in such countries as Mexico, Peru and Guatemala is 20 times lower than in the USA, while in Argentina and Chili - 3 times lower than in the USA (Rojas, 1972). Thus, the picture of mortality overtly points to the environmental factor (to the geographical latitude, as we understand).

But our hypothesis is most convincingly confirmed by data obtained among African populations. We shall present only two examples (Kenya and Nigeria), the reliability of which is beyond doubt. The attention of epidemiologists has been for a long time attracted by data on the tribe of massai, living in the south of this countries and Tanzania. They are traditionally nomadic cattle-breeders and their foods mainly consist of milk, meat of cattle, sheep and goats. Fresh and sour milk, the main product of their daily diet (2-6 L per day) contains a large amount of cholesterol (180-290 mg/L). Thus, they daily consume from 500 to $1500 \mathrm{mg}$ (600 mg on average) of cholesterol, i.e., as much or even more than Americans do. Special morphological and histological examinations of the aorta and coronary arteries revealed no signs of atherosclerosis even in those who died at the age of over 60 with the exception of lipid spots in the aorta which are encountered in American children. No changes in the myocardium were noted (Biss et al., 1970; 1971).

In Nigeria the low incidence of CHD is due to the low incidence of atherosclerosis. In the 8.000 autopsies performed during 10 years myocardial infarction was found in 10 Nigerians, 4 of them had coronary artery embolism due to endocardial fibrosis or bacterial endocarditis (Williams, 1971). We could continue to cite examples of the incidence of CHD in African countries (in Somali nomad as consuming fat enriched camel milk, Bantu tribe in South Africa, etc.). Thus, for example the review of Walker (1975) confirms that in many parts of Africa CHD is not present in Negroes. Even in the large city of Accra with a population of 350.000 individuals for 1968-70 years only 10 patients with CHD were found. Only in Negroes of South Africa mortality from CHD reached $30 \%$ of the total mortality, and this, as we feel, is indicative of the important role of the environment, the geographical latitude of the site of permanent residence, as is also indicated by the picture of morbidity and mortality of Negroes in the USA (Kannel, 1974). 
Epidemiological studies carried out in the seventies in Moscow and Berlin with the use of standardized methods showed that myocardial infarction morbidity in Moscow at the age of 20-64 years is somewhat higher than in Berlin ( 2.87 and 1.52 in males, 1.52 and 1.12 in females, respectively, annually). Increases in age-related morbidity were similar in both populations (Schchwazabaja et al., 1977). The merit of this study is, among things (standardized methods, large sample, etc.) that the populations of these two cities in those years did not differ significantly in the qualitative and quantitative composition of the food consumed. Nevertheless myocardial infarction was more frequent in Moscovites, and, as we feel, it was because of the cooler climate in the capital of Russia.

The role of beverage choice in susceptibility to CHD has aroused interest because populations from countries in which wine consumption is high appear to have lower CHD risk than those from countries in which liquor or beer are more widely favored (St. Leger et al., 1979; Renaud \& de Lorgeril, 1992; Criqui \& Ringel, 1994). France, in particular, has a CHD mortality rate lower than other developed countries despite a similar saturated fat intake and smoking prevalence. This "French paradox" has led to speculation that antioxidant compounds (Seigneur et al., 1990; Siemann \& Creasy, 1993; Frankel et al., 1993) or nonalcoholic antithrombotic effects (Seigneur et al., 1990; Renaud $\&$ de Lorgeril, 1992), especially in red wine, are responsible for some benefit. We would add that of importance here was also the climate of France, as well as the influence of red wine on heat production in the organism.

It is possible that decreased physical activity is not the main reason of CHD. For instance, in Eastern Finland morbidity and mortality from CHD in male loggers (Punsar \& Karvonen, 1973) are extremely high. From the point of view of the authors this is related to the consumption of great amount of saturated fats and cholesterol. We would also add the role of cold and damp air in the woods of Eastern Finland that is breathed by loggers engaged in hard work. It is known that otherwise healthy soldiers after returning from World War II had already arteries occluded by $22 \%$, even though they were 20 years old. We suppose that this was related to the fact that these young subjects had a considerable time in trenches.

\section{Expected Relationship between Variability of Chromosomal Q-heterochromatin and BHC with Atherosclerosis?}

We feel that the present epidemic of atherosclerosis is the result of many processes. The most important among them are changes in the human genome and the heat-conducting characteristics of his body as a result of successfull adaptation of man to temperate and cold climatic zones.

We have extensive data that a modern man has adapted to the climate, different from the climate of East Africa, not with the help of structural genes, but with the involvement of a new type of constitutive heterochromatin chromosomal Q-heterochromatin regions (Q-HRs) (Ibraimov, 1993; 2010; 2015; 2017).

A fundamental feature of chromosomes in higher eukaryotes, including man, is the presence of two evolutionally consolidated types of genetic material: euchromatin and heterochromatin. Euchromatin, the conservative portion of the genome, contains transcribed structural genes, while heterochromatin, the variable portion of the genome, is predominantly composed of nontranscribed repeated DNA sequences.

Heterochromatin has a universal distribution in the chromosomes of all eukaryotes - plants, animals and man, accounting for $10 \%$ to $60 \%$ of their genome. Heterochromatin regions (HRs) account for about $15 \%-20 \%$ of the human genome (Miklos \& John, 1979; Verma \& Dosik, 1980; Stahl \& Hartung, 1981; Prokofyeva-Belgovskaya, 1986; Verma, 1988). Chromosomal HRs does not change during ontogenesis and are inherited in a regular manner as discrete traits.

To-date two types of constitutive heterochromatin are recognized: Q- and C-heterochromatin (Caspersson et al., 1970; Arrighi \& Hsu, 1971; Paris Conference, 1971; Suppl., 1975). There are several significant differences between them: C-heterochromatin is found in the chromosomes of all the higher eukaryotes, while Qheterochromatin - only in man (Homo sapiens), the chimpanzee (Pan troglodytes) and the gorilla (Gorilla gorilla) (Pearson, 1973, 1977).

Chromosomal Q-HRs variability in populations is usually described in the form of three main quantitative characteristics. (1) The distribution of Q-HRs in the population, i.e. distribution of individuals having different numbers of Q-HRs in the karyotype; (2) The derivative of this distribution, an important population characteristic, is the mean number of Q-HRs per individual; (3) Despite the fact that in the human karyotype there are 13 loci in which Q-HRs can be detected (3, 4, 13, 14, 15, 21 and 22 autosomes in both sexes, as well as on the Y chromosome of male) i.e., there could theoretically exist individuals with 25 Q-HRs in their genome, but such cases have not as yet been reported. In individuals of a population the number of Q-HRs usually ranges from 0 to 10 . Distribution of the number of Q-HRs in individuals of a population is almost normal. 
These differences proved to be related to features of the ecological environment of the place of permanent residence, and not to racial and ethnic composition of the population; changes in the amount of Q-HRs in the population genome tend to decrease from southern geographical latitudes to northern ones, and from low-altitude to high-altitude ones (Ibraimov, 2010; 2015; 2017; Ibraimov \& Mirrakhimov, 1982a,b,c; 1985; Ibraimov et al., $1982 ; 1986 ; 1990 ; 1991 ; 1997 ; 2013)$.

For the time being the exact mechanisms of the influence of the amount of Q-HRs on human adaptation to cold are unknown. Nevertheless, the data have already been received about that this type of constitutive heterochromatin, along with $\mathrm{C}$-heterochromatin in the genome, participates in cell thermoregulation, which, in addition, determines the heat conductivity of the body (Ibraimov, 2003; 2004; 2017; Ibraimov et al., 2014). At this it is shown that the amount of Q-HRs in genome is connected with the level of human body heat conductivity (BHC). Results obtained show that individuals in population truly differ from each other in BHC and its level depends on the amount of chromosomal Q-HRs in human genome. In particular, it was established that individuals with the number of chromosomal Q-HRs from 0 to 2 are characterized by a low, from 3 to 5 average, and from 6 or higher of the high BHC (see in details Ibraimov et al., 2014). In addition, in men, the level of BHC is significantly higher than in women. Thus, we encountered another type (for example, types of the human form of constitution) of the hereditary variability of the physical characteristics of the human body in the population.

Unlike many animal species, man is unstable to live in an extreme cold environment. He is basically a tropical homoeothermic. However, due to various reasons, human populations have to live under conditions of low or high environmental temperature where maintaining the temperature homeostasis is especially difficult. Naturally, all three effectors of thermoregulation systems mobilize: heat production, heat loss and thermoregulatory behavior. Though being important, they cannot be effective at long-term perspective. We suppose that $H$. sapiens, besides those inherent in all mammals possesses an additional but very fine and simple mechanism of thermoregulation. In the present case, in order to preserve temperature homeostasis under different environmental conditions, in addition to physiological, behavioral and biochemical mechanisms such as wide intra population variability by BHC was used. Possibly, for the H. sapiens, BHC diversity is necessary because no single genotype can possess a superior adaptadness in all environments (for details see Ibraimov, 1993; 2010; 2015; 2017; Ibraimov et al., 2014).

The conjectured by us role of chromosomal Q-HRs in the pathogenesis of the common forms of atherosclerosis seems extravagant only at first sight. To speak to the point, there are already sufficient grounds to involve the phenomenon of wide quantitative chromosomal Q-HRs and BHC variability in the genome of man in the origin of certain forms of purely human pathology: 1) quantitative polymorphism of chromosomal Q-HRs in a population is only inherent in man; 2) the amount of Q-HRs in the genome of populations living permanently under different climatic conditions differs and depends upon the geographical latitude and altitude above sea-level; 3 ) the amount of Q-HRs in the genome and the level of BHC in patients with alimentary obesity, as well as alcoholism is consistently lower than in healthy individuals, while in drug addicts - vice versa; 4) in newcomers well adapted to the cold climate of Far North and high altitudes (athletes, mountaineers) the amount of Q-HRs in their genome is extremely low as compared with control groups (Ibraimov, 2016a,b; Ibraimov et al., 1990; 1991; 2010).

Thus, wide variability of quantity of chromosomal Q-HRs in man is a sufficiently unique phenomenon, and such a form of hereditary variability is as yet unknown in science. Therefore, without going into details of the problems that are of a purely special nature, let us postulate that the amount of Q-HRs in the genome is very seriously involved in adaptation of man to cold through changes in the heat conductivity of his body. But in the case of atherosclerosis (in breathing cold air and accordingly with a certain cooling of blood) the walls of arteries in individuals with a high BHC apparently are more frequently and more prone to damage.

Experience in biology suggests that nothing will be $100 \%$ and nevertheless we believe that for the development of atherosclerosis the following is necessary: a) the species should be tropical and should live under conditions of temperate and northern latitudes; b) it should have a considerable duration of life (over 45-50 years); c) in the species there should exist a great interindividual and interpopulation difference in BHC. We feel that there would be no atherosclerosis if man continued to live there where he appeared and where his closest fellow-country men, higher primates, still live.

\section{Facts Difficult to Explain by Current Theories}

Let us start with the following question: why among the population of westernized societies the atherosclerotic process reaches a pathological stage more frequently? We suppose that here, besides generally known facts (highfat diet, smoking, lack exercise etc.) and factors with a strong genetic component (elevated levels of LDL/VLDL, lipoprotein, blood pressure, homocysteine, haemostatic factors, reduced levels of HDL, family history, diabetes, gender (male) etc.), of importance is the climatic factor. At present atherosclerosis is most frequently encountered 
in economically developed countries of Western Europe, in USA, Canada, Japan which, as it is known are situated in temperate and northern climatic zones of the northern hemisphere where during definite periods of the day and year man inhales cool or cold atmospheric air.

Facts are known of extremely low incidence or total absence of CHD among the indigenous population in the South, e.g.: Massai tribes in Kenya and Tanzania despite their predominant use of dairy and meat food products (Biss et al., 1970), which could be explained by the temperature of the atmospheric air they breathe. An increase in CHD-induced mortality rate in the populations accompanying the higher geographical latitudes of their places of permanent residence as well as in case of migration of indigenous population from the South to West Europe and Northern America can be accounted for in the same context. CHD is apparently commoner in South Asians (India, Pakistan, Bangladesh and Sri Lanka) in Britain than in general population, despite lower levels of several classic coronary risk factors. We expected that being of South Asian ethnicity may confer an elevated risk factor for cardiovascular disease (Kocher, 1883; Turner, 1933). These geographic differences in lesion distribution within similar ethnic groups strongly suggest that environmental conditions may exert more influence than do racial characteristics on symptomatic atherosclerosis.

A seasonal variation in cardiac mortality has been noted in both the northern and southern hemispheres, with higher death rates during winter than summer. Even on the Hawaii, seasonal variation in mortality from CHD is consistent with reports of greater mortality increase with a given fall of temperature in regions with warm winters (Seto et al., 1998).

It seems to us highly probable that the above facts can be rationally explained within our observations on the distribution of chromosomal Q-HRs in human populations. It is determined that: a) the amount of Q-HRs in the genome of populations living permanently under different climatic conditions differs and depends upon the geographical latitude and altitude above sea-level, the greatest number of Q-HRs is characteristic of natives of subequatorial Africa, while the lowest - aborigines of the Far North of Eastern Siberia and the highlands of the Pamirs and Tien Shan; b) these differences proved to be related to features of the ecological environment of the place of permanent residence, and not to racial and ethnic composition of the population; c) changes in the amount of Q-HRs in the population genome tend to decrease from southern geographical latitudes to northern ones, and from low-altitude to high-altitude ones (Ibraimov, 1993; 2010; 2015).

Observations about that coronary atherosclerosis appears more severe in men than in premenopausal women and below age 60, men develop CHD at more than twice the rate of that in women have not yet received a rational explanation. We suppose that our hypothesis could clarify some contradictory at first sight results obtained - for example in the Charleston Heart Study (Keil et al., 1993). Quote: “...there were no significant racial differences in the rate ratios for death for coronary disease; however, women had significantly lower death rates than men. Over the 30-year period, the mortality rates for coronary disease per 1000 person-years were 5.2 for white men (95 percent confidence interval, 4.1 to 6.3), 4.6 for black men (3.0 to 6.2), 2.1 for white women (1.6 to 2.6), and 3.2 for black women ( 2.3 to 4.0 )" and they conclude that "the major risk factors for mortality from coronary disease were similar in "blacks" and "whites" in the 30-year follow-up of the Charleston Heart Study" (Keil et al., 1993).

We feel that the role of the gender factor, i.e., why CHD develops 2-3 times more frequently in males under 60 than in females, is also related to blood temperature, as it is known that: a) vital capacity in males is greater by 30 $50 \%$; b) they are subject to the influence of cold air longer and stronger than females; c) total blood volume is greater in males than in females; $d$ ) the dimension of the heart itself and the coronary artery lumen are also greater in males; e) males have an abdominal type of breathing, while females have a thoracic type that is known to influence the depth of breathing. Of no less importance is the fact that core temperature differs significantly between men and women, it is higher in the latter (Frank et al., 1997). The influence of the other provocating risk factors on the development of atherosclerosis (smoking, alcohol, hypercholesterolaemia, hormones, etc.) is wellknown. By the way, the atherogenic effect of smoking is related to, among other things, to deep breath after every "inhalation" of the smoke of a cigarette or smoking pipe.

Nevertheless, namely the relatively high heat conductivity of the body of men, compared to women, because they have an amount chromosomal Q-HRs, in average, twice as many as women, makes men more vulnerable to the development of atherosclerosis. The fact is that despite the fact that in the human karyotype Q-HRs can be detected on 4, 13, 14, 15, 21 and 22 autosomes in both sexes, in men on the Y chromosome there is the largest block Qheterochromatin, which can only be seen in the human genome (Paris Conference, 1971; Ibraimov, 2014; 2015).

A natural question arises here: why in warm-blooded carnivorous animals living permanently in the Far North atherosclerosis does not develop? Our answer is that among all mammals living outside of tropical Africa, only humans have the highest BHC, with all the consequences that follow. This assumption has an evolutionary and 
genetic explanation, and it is based on the following facts: a) only in the human genome, in addition to Cheterochromatin, there is chromosomal Q-HRs; b) a new kind of constitutive heterochromatin - Q-heterochromatin - appeared at a later stage of evolution of the animals in the ancestors of three higher primates (Homo sapiens , Pan troglodytes, Gorilla gorilla ) (Paris Conference, 1975; Pearson, 1973, 1977); c) the order Carnivora is quite a unique group among mammals as regards heterochromatin features. Identification of chromosomal Cheterochromatin regions in them by means of C-technique is extremely difficult. And in some representatives of the genus Felix the existing techniques of differential staining of chromosomes fail to identify even centromere heterochromatin (Fredga \& Mandahl, 1972; Pathak \& Wurster-Hill, 1977); d) despite the fact that they constantly inhale cold air, these animals, unlike a human, as a biological species were shaped under these conditions over tens of thousands of years and became adapted to the northern climate at the level of structural genes. Homo sapiens can tolerate cold because each of us carries a tropical microenvironment in the form of clothes and dwellings i.e., adaptation of man is mainly cultural and behavioral. All this may mean that warm-blooded carnivorous animals living permanently in the Far North atherosclerosis does not develop because their bodies, unlike humans, have very low t heat conductivity. Apparently, their known mode of life requires lower heat conductivity inside cells, and possibly inside the whole body. By the way, the question: is man adapted to the climate of Far North or high altitude genetically, remains open (Harrison et al., 1977; Baker, 1978).

And finally, why not all people living in temperate and cold zones or in high altitudes do not suffer from CHD, although to some extent all have atherosclerotic changes on large arteries? In our opinion, this should be expected. The fact is that the individuals in the population differ significantly from each other in the BHC, whose level depends on the number of chromosomal Q-HRs in their genome (Ibraimov et al., 2010; 2014). In other words, we deal with a new, previously unknown form of hereditary variability. By this we also explain why, under all other equal conditions, atherosclerosis does not go into a pathological form not at all people. If our hypothesis is correct, then CHD or brain stroke should develop in people, mainly, high BHC. For example, such epidemiological observations indirectly indicated of this possibility; CHD is apparently commoner in South Asians (India, Pakistan, Bangladesh and Sri Lanka) in Britain than in general population, despite lower levels of several classic coronary risk factors. Here it should be specially noted that the number of chromosomal Q-HRs in the genome of the Indian continent inhabitants is greater than in the populations of Europe (Kalz et al., 2005) or Central Asia (Ibraimov et al., 1997). As well we have showed that the level of BHC at immigrants from India is significantly higher than that of the Russian and Kyrgyz living in Kyrgyzstan (Ibraimov et al., 2010).

\section{How to Test our Hypothesis?}

Our hypothesis is based on the following assumptions:

1) there should arise a slight difference in blood temperature between the venous blood in the right heart and arterial blood in the lung in the process of breathing cold atmospheric air;

2) some components of human plasma may change from "liquid' state to "solid" state when blood temperature falls below $37.0^{\circ} \mathrm{C}$ (phase transition);

3) turbulence appearing after the systole in the left heart contributes to formation of microscopic drops of lipoprotein crystals and fibrous elements in plasma;

4) the known hemodynamic factors impair mechanically the walls of larger arteries with the drop formations until they disappear with recovery of laminar flow in the vessels and blood temperature elevation to $37^{\circ} \mathrm{C}$.

To start, that to test the hypothesis it will be sufficient to:

a) measure in vivo, the blood temperature in the right heart and left heart in conditions of temperature comfort and inhaled cold air;

b) measure the temperature interval of phase transitions of major atherogenous lipoproteins in blood plasma;

c) experimentally determine the degree of atherogenous lipoprotein micro crystals coagulation into larger crystals in turbulent blood flow at different temperatures of the inhaled air;

d) repeat the same experiments on individuals with different numbers of chromosomal Q-HRs and the HNA level.

\section{Acknowledgements}

I apologize to those authors, whose works were not cited, or were cited only through reviews, owing to space limitations. 


\section{References}

Adams, W. C., Fox, R. H., Fry A. J., \& McDonald, I. C. (1975). Thermoregulation during marathon running in cool, moderate, and hot environments. J.Appl. Physiol., 38, 1030-1037.

Arrighi, F. E., \& Hsu, T. C. (1971). Localization of heterochromatin in human chromosomes. Cytogenetics, 10, 81-86.

Baker, P. T. (1978). The biology of high altitude peoples. Cambridge University Press.

Biss, K., Taylor C. B., Lewis L. A., Mikkelson B., Hasscy L. K., \& Jcy Ho, K. (1970). The Massai’s protection against atherosclerosis. Pathol. Microbiol. (Basel), 35(1), 198-204.

Biss, K., Ho, K. J., Mikkelson, B., Lewis, L., \& Taylor, C. B. (1971). Some unique biologic characteristics of the Massai of East Africa. N. Engl. J. Med., Apr. 1, 284(13), 694-699.

Cantor, C. R., \& Schimmel, P. L. (1980). Biophisical Chemistry. W.H. Freeman \& Company. San Francisco.

Caspersson, T., Zech, L., \& Johansson, C. (1970). Differential banding alkilating fluorochromes in human chromosomes. Exp. Cell Res., 60, 315-319.

Chapman, D. (1967). Liquid crystalline nature of phospholipids. Advan. Chem., 63, 157-172.

Criqui, M. H., \& Ringel, B. L. (1994). Does diet or alcohol explain in the French paradox? Lancet, 344, 1719-1723.

Dewan, B. D., Malhotra, K. C., \& Gupta, S. P. (1974). Epidemiological study of coronary heart disease in rural community in Haryana. Ind. Heart J., 26(2), 68-78.

Folkow, B., \& Neil, E. (1971). Circulation. New York: Oxford University Press. London - Toronto.

Frank, S. M., Raja, S. N., Wu, P. K., \& El-Gamal, N. (1997). $\alpha$-Adrenergic mechanisms of thermoregulation in humans. In C. M. Blatties (Ed.), Thermoregulation (pp. 12-20). Ann. New York Acad. Sci., v.813.

Frankel, E. N., Kanner, J., German, J. B., Parks, E., \& Kinsella, J. E. (1993). Inhibition of oxidation of human lowdensity lipoprotein by phenolic substances in red wine. Lancet, 341(8843), 454-457.

Fredga, K., \& Mandahl, N. (1972). Autosomal heterochromatin in some carnivores. In T. Caspersson, \& L. Zech (Eds.), Chromosome Identification. Nobel Symp. (No 23., pp. 104-167). London: Academic Press.

Glagov, S., Zarins, C., Giddens, D. P., \& Ku, D. N. (1988). Hemodynamics and atherosclerosis: insights and perspectives gained from studies of human arteries. Arch. Pathol. Lab. Med., 112, 1018-1031.

Harrison, G. A., Weiner, J. S., Tanner, J. M., \& Barnicot, N. A. (1977). Human Biology. Oxford: Oxford Press.

Ibraimov, A. I. (2008). On the pathogenesis of atherosclerosis: the role of the blood temperature, phase transitions of lipoproteins and turbulence of blood flow. J. Hum. Ecol., 23(3), 195-201.

Ibraimov, A. I. (1993). The origin of modern humans: a cytogenetic model. Hum. Evol., 8, 81-91.

Ibraimov, A. I., \& Mirrakhimov, M. M. (1982a). Human chromosomal polymorphism. III. Chromosomal Qpolymorphism in Mongoloids of northern Asia. Hum. Genet., 62, 252-257.

Ibraimov, A. I., \& Mirrakhimov, M. M. (1982b). Human chromosomal polymorphism. IV. Chromosomal Qpolymorphism in Russians living in Kyrghyzia. Hum. Genet., 62, 258-260.

Ibraimov, A. I., \& Mirrakhimov, M. M. (1982c). Human chromosomal polymorphism. V. Chromosomal Qpolymorphism in African populations. Hum. Genet., 62, 261-265.

Ibraimov, A. I., \& Mirrakhimov, M. M. (1985). Q-band polymorphism in the autosomes and the Y chromosome in human populations. In A. A. Sandberg (Ed.), Progress and Topics in Cytogenetics. The Y chromosome. Part A. Basic Characteristics of the Y chromosome (pp. 213-287). Alan R. Liss Inc., New York.

Ibraimov, A. I., Axenrod, E. I., Kurmanova, G. U., \& Turapov, D. A. (1991). Chromosomal Q-heterochromatin regions in the indigenous population of the northern part of West Siberia and new migrants. Cytobios, 67, 95100.

Ibraimov, A. I. (2003). Condensed chromatin and cell thermoregulation. Complexus, 1, 164-170.

Ibraimov, A. I. (2004). The origin of condensed chromatin, cell thermoregulation and multicellularity. Complexus, 2, 23-34.

Ibraimov, A. I. (2010). Chromosomal Q-heterochromatin regions in populations and human adaptation. In M. K. Bhasin, \& C. Susanne (Eds.), Anthropology Today: Trends and Scope of Human Biology (pp. 225-250). Delhi: Kamla- Raj Enterprises. 
Ibraimov, A. I. (2014). Chromosomal Q-heterochromatin and sex in human population. J. Mol. Biol. Res., 4(1), 10-19. https://doi.org/10.5539/jmbr.v4n1p10

Ibraimov, A. I. (2015). Heterochromatin: The visible with many invisible effects. Global Journal of Medical Research (C), 15(3), 7-32.

Ibraimov, A. I. (2016a). Chromosomal Q-Heterochromatin Polymorphism in Patients with Alimentary Obesity. Biol. Med. (Aligarh), 8, 275. https://doi.org/10.4172/0974-8369.1000275

Ibraimov, A. I. (2016b). Chromosomal Q-heterochromatin Regions in Alcoholics and Drug Addicts. Biol. Med. (Aligarh), 8, 346. https://doi.org/10.4172/0974-8369.1000346

Ibraimov, A. I. (2017) Cell Thermoregulation: Problems, Advances and Perspectives. J. Mol. Biol. Res., 7(1), 5879. https://doi.org/10.5539/jmbr.v7n1p58

Ibraimov, A. I., Akanov, A. A., Meimanaliev, T. S., Sharipov, K. O., Smailova, R. D., \& Dosymbekova, R. (2014). Human Chromosomal Q-heterochromatin Polymorphism and Its Relation to Body Heat Conductivity. Int. J. Genet., 6(1), 142-148.

Ibraimov, A. I., Akanov, A. A., Meymanaliev, T. S., Karakushukova, A. S., Kudrina, N. O., Sharipov, K. O., \& Smailova R. D. (2013). Chromosomal Q-heterochromatin polymorphisms in 3 ethnic groups (Kazakhs, Russians and Uygurs) of Kazakhstan. Int. J.Genet., 5(1), 121-124.

Ibraimov, A. I., Karagulova, G. O., \& Kim, E. Y. (1997). Chromosomal Q-heterochromatin regions in indigenous populations of the Northern India. Ind. J. Hum. Genet., 3(2), 77-81.

Ibraimov, A. I., Kazakova, A. K., Moldotashev, I. K., Sultanmuratov, M. T., \& Abdyev, K. S. (2010). Variability of Human Body Heat Conductivity in Population. I. Methodological and Theoretical Approaches. J. Hum. Ecol., 32(1), 1-22.

Ibraimov, A. I., Kurmanova, G. U., Ginsburg, E. K., Aksenovich, T. I., \& Axenrod, E. I. (1990). Chromosomal Qheterochromatin regions in native highlanders of Pamir and Tien-Shan and in newcomers. Cytobios, 63, 7182.

Ibraimov, A. I., Mirrakhimov, M. M., Axenrod, E. I., \& Kurmanova, G. U. (1986). Human chromosomal polymorphism. IX. Further data on the possible selective value of chromosomal Q-heterochromatin material. Hum. Genet., 73, 151-156.

Ibraimov, A. I., Mirrakhimov, M. M., Nazarenko, S. A., Axenrod, E. I., \& Akbanova G. A. (1982). Human chromosomal polymorphism. I. Chromosomal Q-polymorphism in Mongoloid populations of Central Asia. Hum. Genet., 60, 1-7.

Kalz, L., Kalz-Fuller, B., Hedge, S., \& Schwanitz, G. (2005). Polymorphism of Q-band heterochromatin; qualitative and quantitative analyses of features in 3 ethnic groups (Europeans, Indians, and Turks). Int J Hum Genet, 5(2), 153-163.

Kannel, W. B. (1974). The role of lipids and blood pressure in the development of coronary heart disease. The Framingham study. J. Ital. Cardiol., 4(1), 123-137.

Keil, U., Swales, J. D., \& Grobee, D. E. (1993). Alcohol intake and its relation to hypertension. In P. M. Verschuren (Ed.), Health Issues Related to Alcohol Consumption (pp. 17-42). Washington, DC: ILSI Press.

Keys, A. (Ed.). (1970). Coronary heart disease in seven counties. Amer. Heart Assoc. Monogr. N 29, New York.

Kocher, T. (1883). Uber Kropf exstirpation und ihre Folgen. Arch Klin Chir., 29, 254-337.

Lentz, B. R., Barenholz, Y., \& Thompson, T. E. (1976). Fluorescence depolarization studies of phase transitions and fluidity in phospholipids bilayers. I. Single component phosphatidylcholines liposomes. Biochemistry, $15,4521-4527$.

Lusis, A. J. (2000). Atherosclerosis. Nature, 407, 233-241.

Miclos, G. L. G., \& John, B. (1979). Heterochromatin and satellite DNA in man: properties and prospects. Am. J. Hum. Genet., 31, 264-280.

Paris Conference. (1971), Supplement, 1975. Standartization in human cytogenetics. Birth Defects, XI, 1-84.

Pathak, S., \& Wurster-Hill, D. H. (1977). Distribution of constitutive heterochromatin in carnivores. Cytogenet Cell Genet., 18, 245-254. 
Pearson, P. L. (1973). Banding patterns chromosome polymorphism and primate evolution. Progress in Medical Genetics, 2, 174-197.

Pearson, P. L. (1977). The uniqueness of the human karyotype. In T. Caspersson, \& L. Zech (Eds.), Chromosome identification: technique and applications in biology and medicine. Academic Press, New York, London.

Prokofyeva-Belgovskaya, A. A. (1985). Heterochromatin regions of chromosomes (in Russian). Nauka, Moscow.

Punsar, S., \& Karvonen, M. J. (1973). Angina pectoris and ECG abnormalities in relation to prognosis of coronary heart disease in population studies in Finland. Advanc. Cardiol. (Basel), 8, 148-161.

Renaud, S., \& de Lorgeril, M. (1992). Wine, alcohol, platelets, and the French paradox for coronary heart disease. Lancet, 339, 1523-1526.

Rojas, F. (1972). Interamerican differences in risk. CVD Epidemiology Newsletter, N13, 28-31.

Ross, R. (1993). The pathogenesis of atherosclerosis: a perspective for the 1990s. Nature, 362, 801-809.

Rothen, F., \& Pieranski, P. (1986). Les cristaux colloidaux. La Recherche, 17, 312-321.

Schchwazabaja, I. K., Metelitza, W. J., Anders, G., \& Böthing, Z. (1977). Epidemiology of Cardiovascular Disease. Moscow, (in Russian), "Medicina".

Seigneur, M., Bonnet, J., \& Dorian, B. (1990). Effect of consumption of alcohol, white wine, and red wine on platelet function and serum lipids. J. Appl. Cardiol., 5, 215-222.

Servotham, S. G., \& Berry, J. N. (1968). Prevalence of coronary heart disease in an urban population in Northern India. Circulation, 37(6), 939-953.

Seto, T. B., Mittleman, M. A., Davis, R. B., Taira, D. A., \& Kawachi, I. (1998). Seasonal variation in coronary artery disease mortality in Hawaii: observational study. Brit. Med. J., 316, 1946-1947.

Siemann, E. H., \& Creasy, L. L. (1992). Concentration of the phytoalexin resveratrol in wine. Am. J. Enol. Vitic., $43,1-4$.

Simopoulos, A. P., \& De Meester, F. (2009). A balanced Omega-6/Omega-3 fatty acid ratio, cholesterol and coronary heart disease. In: World Review of Nutrition and Dietetics, Vol. 100, Karger, Basel.

St.Leger, A. S., Cochrane, A. L., \& Moore F. (1979). Factors associated with cardiac mortality in developed countries with particular reference to the consumption of wine. Lancet, 1, 1017-1020.

Stahl, A., \& Hartung, M. (1981). L'heterochromatin. Ann. Genet., 24, 69-77.

Taatjes, D. J., Schneider D. J., Bowill, E. G., \& Sobel, B. E. (2001). Microscopy-based imaging of the pathogenesis of cardiovascular disease. European Microscopy and Analysis (September, pp. 21-23).

Turner, K. B. (1933). "Studies on the prevention of cholesterol atherosclerosis in rabbits". J Exp Med. 58 (1), 115 125.

Tzeng, W. P. (1972). Prevalence of heart diseases in Taipei Urban population. CVD Epidemiology Newsletter, N13, p.27.

Verma, R. S, \& Dosik, H. (1980). Human chromosomal heteromorphisms: nature and clinical significations. Int. Rev. Cytol., 62, 361-383.

Verma, R. S. (1988). Heterochromatin: Molecular and Structural Aspects. Cambridge University Press, Cambridge, New York, New Rochelle, Melbourne, Sydney.

Walker, A. R. P. (1975). The epidemiological emergence of ischemic arterial diseases. Amer. Heart J., 89(2), 133146.

Werner, J., \& Brinck, H. (1997). Induced loco-regional hyperthermia: significance of vascularization. In C. M. Blatties (Ed.), Thermoregulation, Ann. N. Y. Acad. Sci., v.813, 211-218.

Williams, A. O. (1971). Coronary atherosclerosis in Nigeria. Brit. Heart J., 33(1), 95-100.

\section{Copyrights}

Copyright for this article is retained by the author(s), with first publication rights granted to the journal.

This is an open-access article distributed under the terms and conditions of the Creative Commons Attribution license (http://creativecommons.org/licenses/by/4.0/). 